\title{
The Effect of Carbon Monoxide Co-Adsorption on Ni-Catalysed Water Dissociation
}

\author{
Abas Mohsenzadeh ${ }^{1 *}$, Anders Borjesson ${ }^{1, \dagger}$, Jeng-Han Wang ${ }^{2, \dagger}$, Tobias Richards ${ }^{1, \dagger}$ and \\ Kim Bolton ${ }^{1} *$
}

1 School of Engineering, University of Borås, Borås SE 501-90, Sweden;

E-Mails: anders.borjesson@ combine.se (A.B.); tobias.richards@hb.se (T.R.)

2 Department of Chemistry, National Taiwan University, No. 88, Sec. 4, Ting-Chow Rd, Taipei 11677, Taiwan; E-mail: jenghan@ntnu.edu.tw

$\dagger$ These authors contributed equally to this work.

* Authors to whom correspondence should be addressed; E-Mails: abas.mohsenzadeh@hb.se (A.M.); kim.bolton@hb.se (K.B.); Tel.: +46-33-4354487 (A.M.); Fax: +46-33-4354008 (A.M.).

Received: 10 October 2013; in revised form: 12 November 2013 / Accepted: 15 November 2013 / Published: 26 November 2013

\begin{abstract}
The effect of carbon monoxide (CO) co-adsorption on the dissociation of water on the $\mathrm{Ni}(111)$ surface has been studied using density functional theory. The structures of the adsorbed water molecule and of the transition state are changed by the presence of the $\mathrm{CO}$ molecule. The water $\mathrm{O}-\mathrm{H}$ bond that is closest to the $\mathrm{CO}$ is lengthened compared to the structure in the absence of the $\mathrm{CO}$, and the breaking $\mathrm{O}-\mathrm{H}$ bond in the transition state structure has a larger imaginary frequency in the presence of $\mathrm{CO}$. In addition, the distances between the $\mathrm{Ni}$ surface and $\mathrm{H}_{2} \mathrm{O}$ reactant and $\mathrm{OH}$ and $\mathrm{H}$ products decrease in the presence of the $\mathrm{CO}$. The changes in structures and vibrational frequencies lead to a reaction energy that is $0.17 \mathrm{eV}$ less exothermic in the presence of the $\mathrm{CO}$, and an activation barrier that is $0.12 \mathrm{eV}$ larger in the presence of the $\mathrm{CO}$. At $463 \mathrm{~K}$ the water dissociation rate constant is an order of magnitude smaller in the presence of the $\mathrm{CO}$. This reveals that far fewer water molecules will dissociate in the presence of $\mathrm{CO}$ under reaction conditions that are typical for the water-gas-shift reaction.
\end{abstract}

Keywords: water adsorption; water dissociation; nickel; water gas shift reaction; $\mathrm{CO} ; \mathrm{H}_{2} \mathrm{O} ; \mathrm{DFT}$ 


\section{Introduction}

The water gas shift (WGS) reaction, $\mathrm{CO}+\mathrm{H}_{2} \mathrm{O} \rightarrow \mathrm{CO}_{2}+\mathrm{H}_{2}$, is important in many industrial processes, including methanol synthesis and production of hydrogen for use in, e.g., fuel cells. It is also one of the most important reactions in gasification, where carbonaceous materials are converted to a gaseous product that can be used to produce energy or other desirable chemicals [1-5]. The efficiency of the WGS reaction is enhanced in the presence of transition metal catalysts such as nickel, which is widely used due to its high heat conductivity, high catalytic conversion and its capability to be manufactured in different shapes [6-9].

Due to its industrial significance, several experimental and computational investigations have focused on the WGS reaction. Bond et al. proposed a modified route for the gold-catalyzed WGS reaction mechanism by thermal decomposition of a carboxyl species [10]. Steady-state WGS kinetics were determined on ceria-supported Pd, Pt and Rh catalysts by Gorte et al.; they found that the ceria structure significantly affects the results [11]. Shekhar et al. have investigated the promotional effect of alkali additives ( $\mathrm{Na}, \mathrm{Li}$ and $\mathrm{K}$ ) on the WGS reaction for $\mathrm{Pt} / \mathrm{Al}_{2} \mathrm{O}_{3}$ and $\mathrm{Pt} / \mathrm{TiO} 2$ catalysts. They showed that the active platinum remains in the metallic state and that the promotion by alkali is due the modification of the support properties [12]. A density functional theory (DFT) study together with experimental data for the WGS reaction catalyzed by Pt were provided by Gokhale et al. They predicted that that the most significant reaction channel proceeds via a carboxyl intermediate while formate acts only as a spectator species [13]. Furthermore, Cordeiro et al. studied the role of the step sites in the WGS reaction catalyzed by $\mathrm{Cu}$ and found that the associative route through the carboxyl intermediate assisted by co-adsorbed $\mathrm{OH}$ is favored in the presence of steps [14].

The four mechanisms that have been suggested for the WGS reaction are the redox, formate, associative and carbonate mechanisms [15-27]. Previous first principles calculations showed that the most probable reaction mechanisms are the carboxyl and redox mechanisms, and that the rate-limiting step is water dissociation $[14,15,28-33]$.

The catalytic dissociation of water is also important in many other industrial processes, such as steam methane reforming ( $\mathrm{SMR} ; \mathrm{CH}_{4}+\mathrm{H}_{2} \mathrm{O} \rightarrow \mathrm{CO}+3 \mathrm{H}_{2}$ ) where nickel is frequently used as catalyst. The SMR reaction involves the conversion of a hydrocarbon fuel (or an alcohol) into another fuel containing higher heating value. The SMR reaction is widely implemented for production of hydrogen or other useful products [34-36]. The water dissociation is believed to be one of the rate controlling elementary reaction steps in the SMR reaction [37].

The catalytic dissociation of water has been widely studied using both experimental and computational techniques. For example, hydroxyl radical production following Ni-catalyzed water dissociation has been investigated experimentally by Keiser et al. [38]. The hydroxyl radicals were monitored using laser-induced fluorescence and the barrier for their desorption was estimated at different temperatures and pressures. Fajín et al. studied water dissociation on metal surfaces using DFT. They predicted that the nickel surface could be effective for catalyzing water dissociation, that the activation barrier is $0.71 \mathrm{eV}$ and the reaction energy is $-0.37 \mathrm{eV}$ [33]. The binding energies, preferred adsorption sites and configurations for water and its dissociation products $(\mathrm{OH}$ and $\mathrm{H})$ were determined over a number of surfaces, including $\mathrm{Ni}(111)$, by Phatak et al. They found that dissociation of $\mathrm{H}_{2} \mathrm{O}$ to $\mathrm{OH}$ and $\mathrm{H}$ is exothermic on $\mathrm{Ni}(111)$ and the activation and reaction energies are $0.96 \mathrm{eV}$ and $-0.2 \mathrm{eV}$, 
respectively [39]. Several studies have also focused on fundamental aspects of water dissociation on metal surfaces, such as the vibrational modes of the molecular and dissociated water [40-44].

In addition to the WGS reaction discussed above, interaction of $\mathrm{CO}$ with transition metal surfaces is of importance in many catalytic reactions, such as the oxidation of carbon monoxide, $\mathrm{CO}$ methanation and Fischer-Tropsch synthesis [45]. These interactions, including the interactions between adsorbed CO and $\mathrm{H}_{2} \mathrm{O}$, have been investigated over $\mathrm{Ni}(111)$ [46-48]. For example, high resolution electron energy loss spectroscopy (HREELS) measurements by Ellis et al. revealed strong interaction between $\mathrm{H}_{2} \mathrm{O}$ and $\mathrm{CO}$ adsorbed on $\mathrm{Ni}(100)$, where the co-adsorbed $\mathrm{CO}$ changes the water $\mathrm{OH}$ stretching properties [49]. DFT calculations by Lin et al. yielded a reaction energy of $-0.11 \mathrm{eV}$ and an activation barrier of $0.79 \mathrm{eV}$ for water dissociation in the presence of $\mathrm{CO}$ [50]. This reaction energy is less exothermic than those obtained in the absence of $\mathrm{CO}(-0.37$ and $-0.2 \mathrm{eV}$, see above $)$ and the activation barrier lies between the values obtained in the absence of $\mathrm{CO}(0.71$ and $0.96 \mathrm{eV})$. These, and other co-adsorption studies of reactive chemical species on transition-metal catalysts, [51-54] are essential for a more complete understanding of heterogeneous catalysis.

The present contribution extends these previous investigations by using DFT to perform a comparative study of the dissociation of water on a $\mathrm{Ni}(111)$ surface in the absence and presence of co-adsorbed CO. This is the first time that these systems have been studied using the same models and computational methods, and is important since, if the co-adsorbed $\mathrm{CO}$ affects the reactant, transition state or product relative energies or vibrational frequencies, then the water dissociation rate will depend on the presence of $\mathrm{CO}$. For example, the rates may be different for the reaction in a CO-rich WGS and when water dissociates in other processes when $\mathrm{CO}$ is not present. In addition, molecular-level understanding of the water dissociation mechanism which, as discussed above, is a key elementary step in a number of important reactions such as WGS and SMR, will assist in designing more effective catalysts.

\section{Results and Discussion}

\subsection{Adsorption Sites and Energies}

The top (t), hollow hep (h) and hollow fcc (f) sites on the Ni(111) surface are shown in Figure 1. Geometry optimization of the reactants and products was performed on the sites that have previously been shown [50] to yield the lowest energy structures (i.e., the most favorable sites). The lowest energy structures in the absence and presence of $\mathrm{CO}$ are shown in Figures 2 and 3, respectively, and details of these structures are shown in Table 1 . The $*$ in these figures and table indicates that the specie is adsorbed on the surface.

In the absence of $\mathrm{CO}$, the preferred adsorption site for water is the top site $(\mathrm{t})$ via the $\mathrm{O}$ atom. The adsorption energy is $-0.27 \mathrm{eV}$ ( $-0.36 \mathrm{eV}$ without zero point vibrational energy [ZPVE] correction). Both of the $\mathrm{OH}$ and $\mathrm{H}$ products favor the hollow fcc site (f) and, similarly to the water molecule, the $\mathrm{OH}$ is adsorbed via the $\mathrm{O}$ atom. The adsorption energy of these products is $-5.83 \mathrm{eV}(-6.23 \mathrm{eV}$ without ZPVE correction). 
Figure 1. Top (t), hollow hcp (h) and hollow fcc (f) sites on the Ni(111).

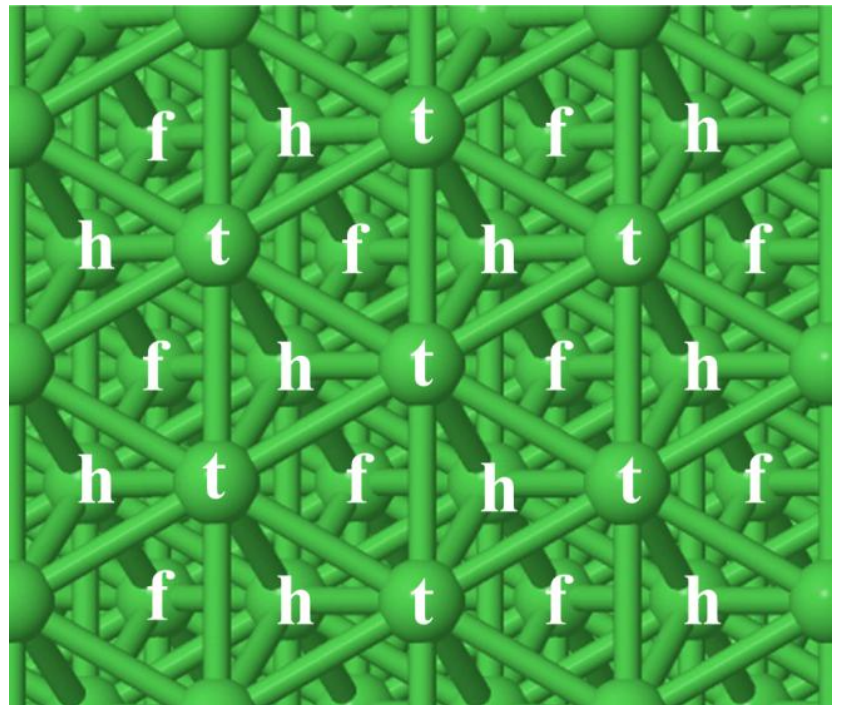

Figure 2. Minimum energy structures of the reactant, transition state and product for the $\mathrm{H}_{2} \mathrm{O}^{*} \rightarrow \mathrm{OH}^{*}+\mathrm{H}^{*}$ reaction.
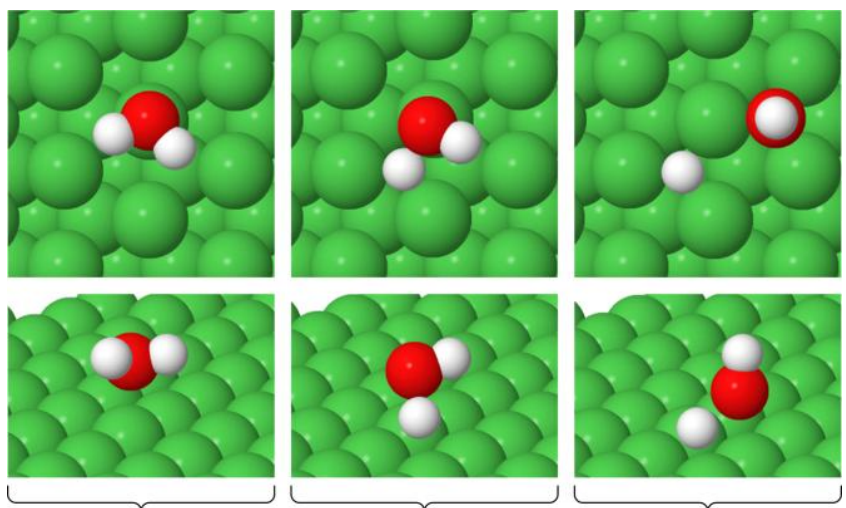

Reactant

Transition state

Product

Figure 3. Minimum energy structures of the reactant, transition state and product for the $\mathrm{H}_{2} \mathrm{O}^{*}+\mathrm{CO}^{*} \rightarrow \mathrm{OH}^{*}+\mathrm{H}^{*}+\mathrm{CO}^{*}$ reaction.
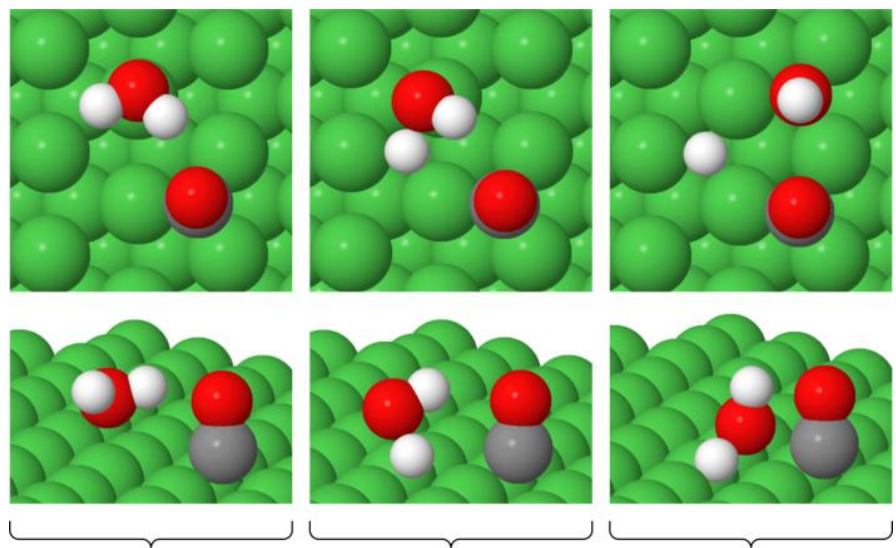

Reactant

Transition state

Product 
Table 1. Adsorption energies (eV), vibrational frequencies $\left(\mathrm{cm}^{-1}\right)$ and structural parameters (A) of reactants and products with and without co-adsorbed carbon monoxide. ${ }^{\text {a }}$

\begin{tabular}{|c|c|c|c|c|c|c|}
\hline Species & Adsorption site & $\mathbf{E}_{\text {ads }}^{\mathbf{e}}$ & $\mathbf{E}_{\text {ads }}^{\mathbf{o}}$ & Vibrational frequencies & $d_{\text {surf-mol }}{ }^{b}$ & Bond length $^{c}$ \\
\hline $\mathrm{H}_{2} \mathrm{O}^{*}$ & $\mathrm{t}$ & -0.36 & -0.27 & $\begin{array}{c}3723,3612,1558,489,427,227, \\
172,122,84\end{array}$ & $\mathrm{H}_{2} \mathrm{O}: 2.157$ & $\begin{array}{l}\mathrm{O}-\mathrm{H}_{\mathrm{a}}: 0.979 ; \\
\mathrm{O}-\mathrm{H}_{\mathrm{b}}: 0.978\end{array}$ \\
\hline $\mathrm{OH}^{*}+\mathrm{H}^{*}$ & OH: f; H: f & -6.23 & -5.83 & $\begin{array}{c}3712,1220,952,776,546,502, \\
387,290,248\end{array}$ & $\begin{array}{l}\text { OH: } 1.950 \\
\text { H: } 1.655\end{array}$ & $\mathrm{O}-\mathrm{H}_{\mathrm{a}}: 0.973$ \\
\hline $\mathrm{H}_{2} \mathrm{O}^{*}+\mathrm{CO}^{*}$ & $\mathrm{H}_{2} \mathrm{O}: \mathrm{t} ; \mathrm{CO}: \mathrm{f}$ & -2.38 & -2.32 & $\begin{array}{c}3721,3412,1662,1566,737, \\
516,379,349,322,306,226, \\
190,149,128,76\end{array}$ & $\begin{array}{l}\mathrm{H}_{2} \mathrm{O}: 2.114 \\
\mathrm{CO}: 1.903\end{array}$ & $\begin{array}{l}\mathrm{O}-\mathrm{H}_{\mathrm{a}}: 0.990 \\
\mathrm{O}-\mathrm{H}_{\mathrm{b}}: 0.975 \\
\mathrm{C}-\mathrm{O}: 1.213\end{array}$ \\
\hline $\mathrm{OH}^{*}+\mathrm{H}^{*}+\mathrm{CO}^{*}$ & $\begin{array}{l}\mathrm{OH}: \mathrm{f} ; \mathrm{H}: \mathrm{f} \\
\quad \mathrm{CO}: \mathrm{f}\end{array}$ & -7.99 & -7.63 & $\begin{array}{c}3704,1761,1253,972,740,567 \\
520,415,395,322,299,277 \\
246,166,122\end{array}$ & $\begin{array}{l}\text { OH: } 1.923 \text {; } \\
\text { H: } 1.646 ; \\
\text { CO: } 1.872\end{array}$ & $\begin{array}{c}\mathrm{O}-\mathrm{H}_{\mathrm{a}}: 0.974 \\
\mathrm{C}-\mathrm{O}: 1.195\end{array}$ \\
\hline
\end{tabular}

The presence of the $\mathrm{CO}$ does not affect the preferred adsorption sites. The favored adsorption site for water is the top site ( $\mathrm{t}$ ) via the $\mathrm{O}$ atom and for carbon monoxide it is the hollow fcc site (f) via the $\mathrm{C}$ atom. The adsorption energy is $-2.32 \mathrm{eV}(-2.38 \mathrm{eV}$ without ZPVE correction). All of the products prefer the hollow fcc site (f), where the $\mathrm{OH}$ is adsorbed via the $\mathrm{O}$ atom and $\mathrm{CO}$ via the $\mathrm{C}$ atom. The adsorption energy is $-7.63 \mathrm{eV}(-7.99 \mathrm{eV}$ without ZPVE correction).

The calculations performed for the higher surface coverages yielded similar results to those presented above. For example, for $1 / 4$ monolayer (only water) and 1/2 monolayer (co-adsorbed water and CO) coverages, the reactant adsorption energies are $-0.20 \mathrm{eV}(-0.26 \mathrm{eV}$ without ZPVE correction) and $-2.43 \mathrm{eV}(-2.35 \mathrm{eV}$ without ZPVE correction), respectively.

Although the presence of the $\mathrm{CO}$ does not affect the preferred adsorption site, it does affect the reactant geometry. In the absence of the $\mathrm{CO}$ the lengths of the $\mathrm{O}-\mathrm{H}$ bonds in the water molecule are almost the same $(0.98 \AA$ ) while, in the presence of $\mathrm{CO}$, the $\mathrm{O}-\mathrm{H}$ bond closest to the $\mathrm{CO}$ molecule is $0.015 \AA$ longer than the other bond. This larger bond length is probably due to interactions between this $\mathrm{H}$ atom and the $\mathrm{CO}$ molecule (the distance between this $\mathrm{H}$ and the $\mathrm{O}$ on the $\mathrm{CO}$ is just $1.88 \AA$ ), although the charge density on this $\mathrm{H}$ atom is the same as the charge density on the other $\mathrm{H}$ atom. This is also reflected in the vibrational frequencies where the asymmetric stretching mode is lowered by $200 \mathrm{~cm}^{-1}$ (from 3612 to $3412 \mathrm{~cm}^{-1}$ in the absence and presence of $\mathrm{CO}$, respectively). The presence of the $\mathrm{CO}$ does not have a significant effect on the $\mathrm{OH}$ product geometry or vibrational frequency.

The co-adsorbed $\mathrm{CO}$ also affects the distance between the reactant and products with the Ni surface (defined as the shortest distance between any atom of the adsorbate and any metal atom on the surface). The distance between the $\mathrm{H}_{2} \mathrm{O}$ and the surface decreases from $2.157 \AA$ to $2.114 \AA$ when the $\mathrm{CO}$ is present, for $\mathrm{OH}$ the decrease is from $1.950 \AA$ to $1.923 \AA$, and for $\mathrm{H}$ the decrease is from $1.655 \AA$ to $1.646 \AA$. The reason that the presence of the $\mathrm{CO}$ molecule decreases the height of the reactant and products above the surface is probably due to electron transfer from the $\mathrm{CO}$ to the Ni surface. In the presence of the $\mathrm{CO}$ the total charge density on the uppermost $\mathrm{Ni}$ atoms is 0.63 e more than in the absence of the $\mathrm{CO}$. This increases the interaction strengths (and hence decreases the bond lengths) between the surface and the 
adsorbants, which is also seen by an increase in the charge density on the $\mathrm{H}_{2} \mathrm{O}, \mathrm{OH}$ and $\mathrm{H}$ adsorbants by $0.01,0.04$ and $0.03 \mathrm{e}$, respectively.

\subsection{Transition States and Reaction Energies}

Table 2 shows the data of the transition states together with reaction rate constants at $463 \mathrm{~K}$, which is typical for low-temperature processes that include the WGS reaction [55]. The activation energy $\left(\mathrm{E}_{\mathrm{a}}\right)$ without co-adsorbed $\mathrm{CO}$ is $0.75 \mathrm{eV}(0.96 \mathrm{eV}$ without ZPVE correction) and in the presence of $\mathrm{CO}$ it increases to $0.87 \mathrm{eV}$ (1.09 eV without ZPVE correction), respectively. The activation energy in the absence of $\mathrm{CO}$ is in agreement with that obtained by Fajín et al. $(0.71 \mathrm{eV})$. Similarly, the value determined in the presence of $\mathrm{CO}$ is similar to the value of $0.79 \mathrm{eV}$ reported by Lin et al. The same trend is found for higher coverages. For the $1 / 4$ and $1 / 2$ monolayer surfaces the activation barrier in the absence of $\mathrm{CO}$ is $0.69 \mathrm{eV}(0.87 \mathrm{eV}$ without ZPVE correction) and in the presence of $\mathrm{CO}$ it is $1.18 \mathrm{eV}$ (1.39 eV without ZPVE correction). Hence, the presence of CO increases the activation energy at both surface coverages.

Table 2. Activation energies $(\mathrm{eV})$, vibrational frequencies $\left(\mathrm{cm}^{-1}\right)$, reaction rate constant at $463 \mathrm{~K}\left(\mathrm{~s}^{-1}\right)$, reaction energy $(\mathrm{eV})$, length of the breaking $\mathrm{OH}$ bond at the transition state and its imaginary frequency $\left(\mathrm{cm}^{-1}\right)$, with and without co-adsorbed carbon monoxide. ${ }^{\text {a }}$

\begin{tabular}{|c|c|c|c|c|c|c|c|c|}
\hline Species & $\mathbf{E}_{\mathbf{a}}^{\mathbf{e}}$ & $\mathbf{E}_{\mathbf{a}}^{\mathbf{o}}$ & Vibrational modes & $k$ & $\mathbf{E}_{\text {react }}^{\mathrm{e}}$ & $\mathbf{E}_{\text {react }}^{\mathbf{o}}$ & $\mathbf{d}_{\mathrm{O}-\mathrm{H}}$ & $\begin{array}{l}\text { Imaginary } \\
\text { frequency }\end{array}$ \\
\hline $\mathrm{H}_{2} \mathrm{O}^{*} \rightarrow \mathrm{OH}^{*}+\mathrm{H}^{*}$ & 0.96 & 0.75 & $\begin{array}{c}3653,837,748,677, \\
432,393,167,71\end{array}$ & $2.03 \times 10^{4}$ & -0.30 & -0.41 & 1.559 & 797 \\
\hline $\mathrm{H}_{2} \mathrm{O}^{*}+\mathrm{CO}^{*} \rightarrow \mathrm{OH}^{*}+\mathrm{H}^{*}+\mathrm{CO}^{*}$ & 1.09 & 0.87 & $\begin{array}{c}3623,1726,921,765 \\
690,465,400,377,324, \\
282,162,147,136,105\end{array}$ & $1.76 \times 10^{3}$ & -0.05 & -0.17 & 1.560 & 817 \\
\hline
\end{tabular}

${ }^{a}$ For the activation energies $\left(\mathrm{E}_{\mathrm{a}}\right)$, “e” and "o" denote the uncorrected and ZPVE-corrected values, respectively.

The length of the breaking $\mathrm{O}-\mathrm{H}$ bond is not significantly influenced by $\mathrm{CO}$ co-adsorption, and its (imaginary) vibrational frequency is increased by only $20 \mathrm{~cm}^{-1}$. This means that the reaction barrier is slightly narrower in the presence of the CO. However, this effect is not as significant as it is for the water reactant, where the presence of the $\mathrm{CO}$ decreased the asymmetric vibrational mode frequency by $200 \mathrm{~cm}^{-1}$.

Unlike the length and frequency of the breaking bond, the reaction rate constant changes considerably when $\mathrm{CO}$ is present, decreasing from $2.03 \times 10^{4} \mathrm{~s}^{-1}$ to $1.76 \times 10^{3} \mathrm{~s}^{-1}$. The rate constant in the absence of $\mathrm{CO}$ is smaller than the value of $7.1 \times 10^{4} \mathrm{~s}^{-1}$ obtained by Fajín et al. [33]. This may be due to the convergence criteria, since repeating the above calculation, but with coarser convergence criteria of $10^{-5} \mathrm{eV}$ for the total energy and $10^{-2} \mathrm{eV} / \AA$ for the forces acting on ions, yields the same result as that reported by Fajín et al.

The reaction energy $\left(\mathrm{E}_{\text {react }}\right)$, which is the difference between the product and reactant energies, is significantly affected by the presence of co-adsorbed CO. In the absence of $\mathrm{CO} \mathrm{E}_{\text {react }}=-0.41 \mathrm{eV}$ $(-0.30 \mathrm{eV}$ without $\mathrm{ZPVE}$ correction) which is $0.24 \mathrm{eV}$ more exothermic than the reaction energy in the presence of $\mathrm{CO}$, which is $-0.17 \mathrm{eV}(-0.05 \mathrm{eV}$ without $\mathrm{ZPVE}$ correction). The reaction energy calculated 
in the absence of $\mathrm{CO}$ is similar to that obtained by Fajín et al. $(-0.31 \mathrm{eV})$. Similarly, the calculated reaction energy in the presence of co-adsorbed $\mathrm{CO}$ is similar to the value of $-0.11 \mathrm{eV}$ obtained by Line et al. [33,50].

A comparison of the reaction profiles with and without adsorbed carbon monoxide is shown in Figure 4. As discussed above, the co-adsorbed $\mathrm{CO}$ increases the activation barrier by $0.12 \mathrm{eV}$ and decreases the exothermicity by $0.24 \mathrm{eV}$. A possible reason for the larger activation energy is that the $\mathrm{CO}$ (and Ni surface) induces a larger change in the structure of the water molecule when going from reactant to transition state. To investigate these we performed single point energy calculations on the water molecule (in vacuum) in its reactant and transition state structures. It was seen that this does not explain the trends seen in Figure 4, since the energy of the water molecule in the transition state structure is lower than the energy in the reactant structure, and hence it is changes in the $\mathrm{CO}$, Ni surface or interactions between the water-CO-Ni that lead to the increase in energy at the transition state. Similarly, calculations comparing the energies of the reactant water and product $\mathrm{H}$ and $\mathrm{OH}$ structures showed that this cannot explain the decrease in exothermicity in the presence of the $\mathrm{CO}$. In fact, when comparing the $\mathrm{H}_{2} \mathrm{O}$ and $(\mathrm{H}+\mathrm{OH})$ energies the reaction is endothermic when using the structures from the both systems (in the absence and presence of the $\mathrm{CO}$ ).

Figure 4. Reaction profiles for the water dissociation with (dashed line) and without (solid line) co-adsorbed CO.

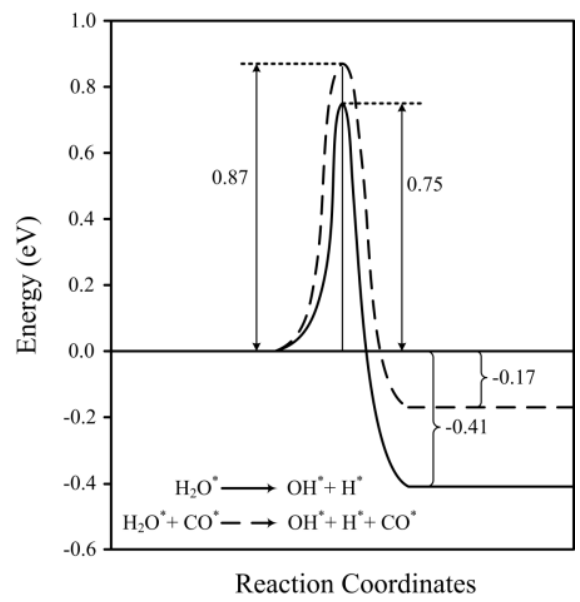

These calculations were repeated but where the $\mathrm{CO}$ molecule was included (together with the water molecule). This was done to ascertain whether it is changes in the $\mathrm{CO}$ molecule and/or interactions between the $\mathrm{H}_{2} \mathrm{O}$ and $\mathrm{CO}$ that leads to an increase in the transition state energy compared to the energy of the reactant. Once again, the $\mathrm{H}_{2} \mathrm{O}-\mathrm{CO}$ energy (in the vacuum) of the transition state structure was lower than the energy of the reactant structure, and the reaction is more exothermic than that when using the structures from the system that does not contain $\mathrm{CO}$ (thus opposite to what is observed in Figure 4).

Hence, it is the interplay between all three components - the $\mathrm{H}_{2} \mathrm{O}, \mathrm{CO}$ and Ni surface - that leads to the reaction profiles seen in Figure 4. As discussed above, the presence of the $\mathrm{CO}$ on the surface leads to stronger interactions between the $\mathrm{Ni}$ surface and the $\mathrm{H}_{2} \mathrm{O}$ reactant and $\mathrm{H}$ and $\mathrm{OH}$ products. The larger activation energy and decreased exothermicity indicates that the stability induced by the surface in the presence of $\mathrm{CO}$ is larger for the reactant than for the transition state and product structures. 
Figure 5 shows the effect of temperature on the reaction rate constant. The data is also shown in its Arrhenius form in the inset to the figure. The difference in reaction rate constants in the absence and presence of $\mathrm{CO}$ increases with increasing temperature, showing that it becomes even more important to consider the effect of $\mathrm{CO}$ co-adsorption at higher temperatures.

Figure 5. Temperature dependence of the reaction rate constant for the water dissociation reaction with and without co-adsorbed carbon monoxide. The Arrhenius format of the data is shown in the inset.

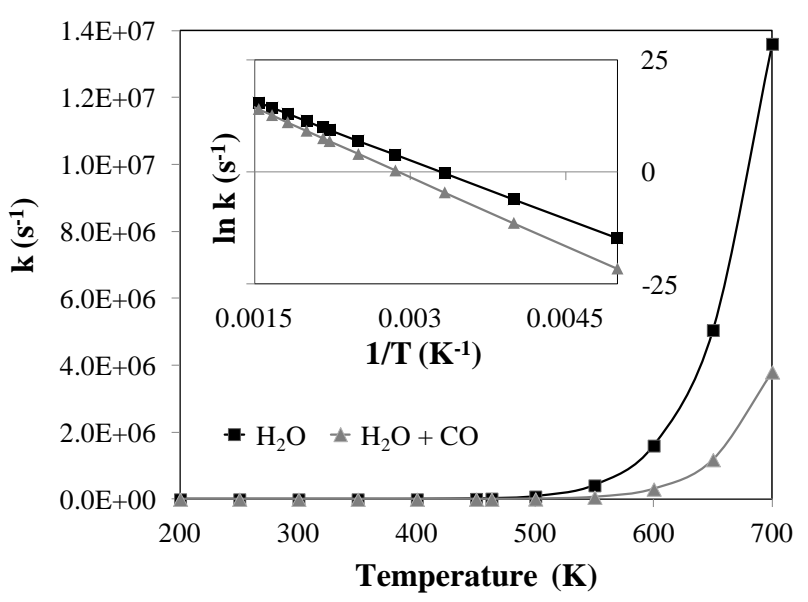

\section{Methods and Models}

The calculations were performed with the Vienna ab initio simulation package (VASP) [56-59] using spin polarized DFT. The Perdew-Burke-Ernzerhof generalized gradient approach (GGA-PBE) [60] to the exchange-correlation potential was implemented and the projector-augmented wave method (PAW) [61,62] was applied to the basis set to account for the effect of the core electrons in the valence electron density. A $600-\mathrm{eV}$ cutoff for the plane waves expansion was applied and a $4 \times 4 \times 1$ Monkhorst-Pack grid of $k$-points [63] was used for the numerical integration in reciprocal space. As shown previously [50] smaller Brillouin zone (BZ) sampling intervals $(5 \times 5 \times 1$ and $6 \times 6 \times 1)$ and higher cutoff energies (700 and $800 \mathrm{eV}$ ) show insignificant differences in the energies of the optimized structures (less than $0.01 \mathrm{eV}$ ). Hence, the cutoff and Monkhorst-Pack grid used here yield converged results.

The surface orientation, as well as steps and defects on the surface, could affect its catalytic properties and reactions energies [14,64]. The face-centered cubic (fcc) nickel, Ni(111), is the most stable Ni surface and is therefore commonly used in computational studies of heterogeneous catalytic reactions [65-69]. This surface was also used in the present work, where periodic boundary conditions were imposed in two directions to model a semi-infinite crystal surface. Tests showed that a Ni(111) surface containing $4 \times 4$ unit cells in each layer, and with five layers that are separated by an equivalent volume of vacuum in the surface perpendicular direction, yield converged results in a computationally tractable time. The two bottom layers of the slab were fixed to maintain the bulk crystal structure, and the three upper layers were free to relax. This periodic box size, which yields a 1/16 monolayer coverage for the water in the absence of $\mathrm{CO}$ and a $1 / 8$ monolayer for the co-adsorbed $\mathrm{CO}$ and water, prevents interactions between the surface atoms and adsorbates with their periodic images. Higher surface 
coverages, including $1 / 4$ and 1/2 monolayer, were also investigated to elucidate if the trends reported here are sensitive to the surface coverage.

The conjugate-gradient (CG) method was used to obtain the geometry optimized structures of the adsorbates on the surface. The convergence criteria were $10^{-6} \mathrm{eV}$ for the total energy and $10^{-3} \mathrm{eV} / \AA$ for the forces acting on the ions.

Transition states were identified using an improved version of the nudged elastic band (NEB) method, called climbing-image NEB (CI-NEB) [70,71]. In this method, the lowest energy reactant and product configurations are selected as the initial and final states, and 6 images were placed along the minimum energy path (MEP). A $-0.5 \mathrm{eV}^{-2}$ spring force constant between images was used. Due to computational constraints, a smaller set of $k$-points $(2 \times 2 \times 1)$ and a lower energy cutoff $(400 \mathrm{eV})$ was used to relax all the images until the maximum force acting on an atom was less than $0.01 \mathrm{eV}$. Single point energy calculations at the transition state using $4 \times 4 \times 1 k$-mesh and $600 \mathrm{eV}$ cut off showed that the activation energy differs from that obtained with the less accurate settings by at most $0.02 \mathrm{eV}$.

Vibrational frequencies were calculated at all stationary points to ensure that they were minimum energy (zero imaginary frequencies) or transition states (one imaginary frequency) geometries, as well as to determine the zero point vibrational energies (ZPVEs) and partition functions. The frequencies were determined by diagonalizing a finite difference construction of the Hessian matrix using displacements of $0.01 \AA$ (only the adsorbates were allowed to move).

The adsorption energies $\left(E_{a d s}\right)$ of the reactants and products were calculated from Equation (1).

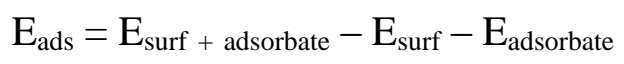

where $\mathrm{E}_{\text {surf }}$ is the total energy of the $\mathrm{Ni}(111)$ surface, $\mathrm{E}_{\text {adsorbate }}$ is the total energy of the isolated, geometry optimized adsorbate(s) in the gas phase and $\mathrm{E}_{\text {surf }}+$ adsorbate is the total energy of the surface-adsorbate(s) system. Results of $E_{\text {ads }}$ where ZPVE corrections are excluded ( $E_{\text {ads }}^{e}$ ) and included ( $\left.E_{\text {ads }}^{o}\right)$ are given below for the sake of completeness and to show the importance of this correction.

The water dissociation rate constant $(k)$ was estimated using transition state theory [72], i.e., Equation (2).

$$
k_{\mathrm{TST}}=\left(\frac{k_{B} T}{h}\right)\left(\frac{q^{\#}}{q}\right) \mathrm{e}^{\frac{-\mathrm{E}_{\mathrm{a}}}{k_{B} \mathrm{~T}}}
$$

where $k_{B}$ is Boltzmann's constant, $T$ is the absolute temperature, $h$ is Planck's constant and $\mathrm{E}_{\mathrm{a}}$ is the activation energy from the ZPVE corrected energies. $q$ and $q^{\#}$ are the partition functions for the reactant and the transition state respectively. Similarly to previous studies $[14,33,73]$, the partition functions have been calculated assuming harmonic vibrations. Although this approximation may well affect the quantitative results presented here, it is not expected to affect the trends.

The effect of the $\mathrm{CO}$ on the reactant, transition state and product geometries was analyzed using the atomic charge densities. These calculations were performed using $2 \times 2$ unit cells in each layer, since these cells yield the same geometric and energetic trends as the larger unit cells. The charge density on each ion in the relaxed structure is calculated by integrating the valence charge density within the Wigner-Seitz spheres around each atom. This radius is selected such that the total volume over all atoms is approximately $100 \%$ and that the ratios of the atomic radii is equal to that of the ionic radii [74]. The present calculations use a $8 \times 8 \times 1 k$-point meshes and Wigner-Seitz radii equal to 
$1.4 \AA$ for Ni, $1.29 \AA$ for carbon, $1.11 \AA$ for oxygen and $0.7 \AA$ for hydrogen. Altering these radii by up to $10 \%$ does not change the trends reported here.

\section{Conclusions}

The effect of $\mathrm{CO}$ co-adsorption on water dissociation over the $\mathrm{Ni}(111)$ nickel surface has been studied using DFT calculations. The results show that the co-adsorption of $\mathrm{CO}$ alters the geometry of the adsorbed reactant water molecule. The $\mathrm{O}-\mathrm{H}$ bond that is closest to the $\mathrm{CO}$ is lengthened and weakened. In addition, the distance between the reactants and products with the surface decreases in the presence of the co-adsorbed $\mathrm{CO}$. These changes result in a dissociation energy that is $0.24 \mathrm{eV}$ less exothermic in the presence of the $\mathrm{CO}$.

The results also show that the activation energy for water dissociation increases by $0.12 \mathrm{eV}$ in the presence of the co-adsorbed CO. In addition, the breaking $\mathrm{O}-\mathrm{H}$ bond at the transition state has a slightly larger imaginary vibrational frequency in the presence of the co-adsorbed $\mathrm{CO}$. These changes (including changes in the reactant geometries and vibrational frequencies) lead to a considerable decrease in the rate constant when $\mathrm{CO}$ is present. At typical low-temperature process conditions of $463 \mathrm{~K}$, the rate constant in the presence of $\mathrm{CO}$ is approximately twelve times smaller than in the absence of $\mathrm{CO}$, and this difference increases with increasing temperature. Hence, it is important to account for co-adsorbed $\mathrm{CO}$ when Ni-catalyzed water dissociation occurs in a CO-rich environment.

\section{Acknowledgments}

This research presented here was funded by the Stiftelsen Föreningssparbanken Sjuhärad. The computations and simulations were performed on resources provided by the Swedish National Infrastructure for Computing (SNIC) at PDC Centre for High Performance Computing (PDC-HPC) and the Uppsala Multidisciplinary Center for Advanced Computational Science (UPPMAX), as well as the Abel resource (Oslo, Norway) provided by PRACE.

\section{Conflicts of Interest}

The authors declare no conflict of interest.

\section{References}

1. Higman, C.; van der Burgt, M. Gasification, 2nd ed.; Gulf Professional Publishing: Jordan Hill, Oxford, UK, 2008.

2. Yu, J.; Tian, F.; Chow, M.; McKenzie, L.; Li, C. Effect of iron on the gasification of Victorian brown coal with steam: Enhancement of hydrogen production. Fuel 2006, 85, 127-133.

3. Rozovskii, A.; Lin, G. Fundamentals of methanol synthesis and decomposition. Top. Catal. 2003, 22, 137-150.

4. Larrubia Vargas, M.A.; Busca, G.; Costantino, U.; Marmottini, F.; Montanari, T.; Patrono, P.; Pinzari, F.; Ramis, G. An IR study of methanol steam reforming over ex-hydrotalcite $\mathrm{Cu}-\mathrm{Zn}-\mathrm{Al}$ catalysts. J. Mol. Catal. A 2007, 266, 188-197. 
5. Lee, S.H.D.; Applegate, D.V.; Ahmed, S.; Calderone, S.G.; Harvey, T.L. Hydrogen from natural gas: Part I-Autothermal reforming in an integrated fuel processor. Int. J. Hydrogen Energy 2005, 30, 829-842.

6. Callaghan, C.A. Kinetics and catalysis of the water-gas-shift reaction: A microkinetic and graph theoretic approach. Master's Thesis, Worcester Polytechnic Institute, Worceste, MA, USA, 2006.

7. Hwang, K.-R.; Lee, C.-B.; Park, J.-S. Advanced nickel metal catalyst for water-gas shift reaction. J. Power Sources 2011, 196, 1349-1352.

8. Li, Y.; Fu, Q.; Flytzani-Stephanopoulos, M. Low-temperature water-gas shift reaction over $\mathrm{Cu}$ - and Ni-loaded cerium oxide catalysts. Appl. Catal. B 2000, 27, 179-191.

9. Kim, S.H.; Nam, S.-W.; Lim, T.-H.; Lee, H.-I. Effect of pretreatment on the activity of Ni catalyst for CO removal reaction by water-gas shift and methanation. Appl. Catal. B 2008, 81, 97-104.

10. Bond, G. Mechanisms of the gold-catalysed water-gas shift. Gold. Bull. 2009, 42, 337-342.

11. Bunluesin, T.; Gorte, R.J.; Graham, G.W. Studies of the water-gas-shift reaction on ceria-supported Pt, Pd, and Rh: Implications for oxygen-storage properties. Appl. Catal. B 1998, 15, $107-114$.

12. Pazmiño, J.H.; Shekhar, M.; Damion Williams, W.; Cem Akatay, M.; Miller, J.T.; Nicholas Delgass, W.; Ribeiro, F.H. Metallic Pt as active sites for the water-gas shift reaction on alkali-promoted supported catalysts. J. Catal. 2012, 286, 279-286.

13. Grabow, L.C.; Gokhale, A.A.; Evans, S.T.; Dumesic, J.A.; Mavrikakis, M. Mechanism of the water gas shift reaction on Pt: First principles, experiments, and microkinetic modeling. J. Phys. Chem. C 2008, 112, 4608-4617.

14. Fajín, J.L.; Cordeiro, M.; Illas, F.; Gomes, J.R. Influence of step sites in the molecular mechanism of the water gas shift reaction catalyzed by copper. J. Catal. 2009, 268, 131-141.

15. Nakamura, J.; Campbell, J.M.; Campbell, C.T. Kinetics and mechanism of the water-gas shift reaction catalysed by the clean and Cs-promoted $\mathrm{Cu}$ (110) surface: A comparison with $\mathrm{Cu}(111)$. J. Chem. Soc. Faraday Trans. 1990, 86, 2725-2734.

16. Ovesen, C.; Stoltze, P.; Nørskov, J.; Campbell, C. A kinetic model of the water gas shift reaction. J. Catal. 1992, 134, 445-468.

17. Ovesen, C.; Clausen, B.; Hammershøi, B.; Steffensen, G.; Askgaard, T.; Chorkendorff, I.; Nørskov, J.K.; Rasmussen, P.; Stoltze, P.; Taylor, P. A microkinetic analysis of the water-gas shift reaction under industrial conditions. J. Catal. 1996, 158, 170-180.

18. Campbell, C.T.; Daube, K. A surface science investigation of the water-gas shift reaction on $\mathrm{Cu}(111)$. J. Catal. 1987, 104, 109-119.

19. Froment, G.F.; Waugh, K. Dynamics of Surfaces and Reaction Kinetics in Heterogeneous Catalysis; Froment, G.F., Waugh, K.C., Eds.; Elsevier Science: Amsterdam, The Netherlands, 1997; Volume 109.

20. Waugh, K.C. Prediction of global reaction kinetics by solution of the Arrhenius parameterised component elementary reactions: Microkinetic analysis. Catal. Today 1999, 53, 161-176.

21. Fishtik, I.; Datta, R. A UBI-QEP microkinetic model for the water-gas shift reaction on $\mathrm{Cu}(111)$. Surf. Sci. 2002, 512, 229-254.

22. Rhodes, C.; Hutchings, G.; Ward, A. Water-gas shift reaction: Finding the mechanistic boundary. Catal. Today 1995, 23, 43-58. 
23. Askgaard, T.; Norskov, J.; Ovesen, C.; Stoltze, P. A kinetic model of methanol synthesis. J. Catal. 1995, 156, 229-242.

24. Van Herwijnen, T.; de Jong, W. Kinetics and mechanism of the CO shift on CuZnO: 1. Kinetics of the forward and reverse CO shift reactions. J. Catal. 1980, 63, 83-93.

25. Callaghan, C.; Fishtik, I.; Datta, R.; Carpenter, M.; Chmielewski, M.; Lugo, A. An improved microkinetic model for the water gas shift reaction on copper. Surf. Sci. 2003, 541, 21-30.

26. Lund, C.R. Water-gas shift kinetics over iron oxide catalysts at membrane reactor conditions. Final Rep. Chem. Eng. Dep. Univ. Buffalo 2002, 14260-14200.

27. Ma, D.; Lund, C.R. Assessing high-temperature water-gas shift membrane reactors. Ind. Eng. Chem. Res. 2003, 42, 711-717.

28. Rodriguez, J.A.; Graciani, J.; Evans, J.; Park, J.B.; Yang, F.; Stacchiola, D.; Senanayake, S.D.; Ma, S.; Pérez, M.; Liu, P. Water-gas shift reaction on a highly active inverse $\mathrm{CeOx} / \mathrm{Cu}(111)$ catalyst: Unique role of ceria nanoparticles. Angew. Chem. 2009, 121, 8191-8194.

29. Rodriguez, J.; Ma, S.; Liu, P.; Hrbek, J.; Evans, J.; Perez, M. Activity of CeOx and TiOx nanoparticles grown on $\mathrm{Au}(111)$ in the water-gas shift reaction. Science 2007, 318, 1757-1760.

30. Huang, S.-C.; Lin, C.-H.; Wang, J.-H. Trends of water gas shift reaction on close-packed transition metal surfaces. J. Phys. Chem. C 2010, 114, 9826-9834.

31. Park, J.B.; Graciani, J.; Evans, J.; Stacchiola, D.; Senanayake, S.D.; Barrio, L.; Liu, P.; Sanz, J.F.; Hrbek, J.; Rodriguez, J.A. Gold, copper, and platinum nanoparticles dispersed on $\mathrm{CeOx} / \mathrm{TiO} 2(110)$ surfaces: High water-gas shift activity and the nature of the mixed-metal oxide at the nanometer level. J. Am. Chem. Soc. 2009, 132, 356-363.

32. Gokhale, A.A.; Dumesic, J.A.; Mavrikakis, M. On the mechanism of low-temperature water gas shift reaction on copper. J. Am. Chem. Soc. 2008, 130, 1402-1414.

33. Fajín, J.L.; Cordeiro, M.; Illas, F.; Gomes, J.R. Descriptors controlling the catalytic activity of metallic surfaces toward water splitting. J. Catal. 2010, 276, 92-100.

34. Blaylock, D.W.; Ogura, T.; Green, W.H.; Beran, G.J. Computational investigation of thermochemistry and kinetics of steam methane reforming on $\mathrm{Ni}(111)$ under realistic conditions. J. Phys. Chem. C 2009, 113, 4898-4908.

35. Zhu, T.; van Grootel, P.W.; Filot, I.A.; Sun, S.-G.; van Santen, R.A.; Hensen, E.J. Microkinetics of steam methane reforming on platinum and rhodium metal surfaces. J. Catal. 2012, 297, 227-235.

36. Rostrup-Nielsen, J.R.; Sehested, J.; Nørskov, J.K. Hydrogen and synthesis gas by steam- and $\mathrm{CO}_{2}$ reforming. Adv. Catal. 2002, 47, 65-139.

37. Van Grootel, P.W.; Hensen, E.J.M.; van Santen, R.A. DFT study on $\mathrm{H}_{2} \mathrm{O}$ activation by stepped and planar Rh surfaces. Surf. Sci. 2009, 603, 3275-3281.

38. Keiser, J.; Hoffbauer, M.; Lin, M. Production of hydroxyl on polycrystalline nickel studied by thermal desorption/laser-induced fluorescence. J. Phys. Chem. 1985, 89, 2635-2638.

39. Phatak, A.A.; Delgass, W.N.; Ribeiro, F.H.; Schneider, W.F. Density functional theory comparison of water dissociation steps on $\mathrm{Cu}, \mathrm{Au}, \mathrm{Ni}, \mathrm{Pd}$, and Pt. J. Phys. Chem. C 2009, 113, 7269-7276.

40. Henderson, M.A. The interaction of water with solid surfaces: Fundamental aspects revisited. Surf. Sci. Rep. 2002, 46, 1-308.

41. Politano, A.; Chiarello, G. Enhancement of hydrolysis in alkali ultrathin layers on metal substrates in the presence of electron confinement. Chem. Phys. Lett. 2010, 494, 84-87. 
42. Liu, K.; Gao, S. Water adsorption on $\mathrm{Na} / \mathrm{Cu}(111)$ : State-specific coupling with quantum well states. J. Phys. Chem. C 2012, 116, 17613-17618.

43. Meng, S.; Wang, E.; Gao, S. Water adsorption on metal surfaces: A general picture from density functional theory studies. Phys. Rev. B 2004, 69, 195404.

44. Meng, S.; Xu, L.; Wang, E.; Gao, S. Vibrational recognition of hydrogen-bonded water networks on a metal surface. Phys. Rev. Lett. 2002, 89, 176104.

45. Somorjai, G.A.; Li, Y. Introduction to surface chemistry and catalysis, 2nd ed.; Wiley: Hoboken, NJ, USA, 2010.

46. Morikawa, Y.; Mortensen, J.J.; Hammer, B.; Nørskov, J.K. CO adsorption and dissociation on $\operatorname{Pt}(111)$ and Ni(111) surfaces. Surf. Sci. 1997, 386, 67-72.

47. Christmann, K.; Schober, O.; Ertl, G. Adsorption of CO on a Ni(111) surface. J. Chem. Phys. 1974, 60, 4719.

48. Netzer, F.P.; Madey, T.E. The structure of CO on Ni(111). J. Chem. Phys. 1982, 76, 710.

49. Ellis, T.; Kruus, E.; Wang, H. The interaction between water and carbon monoxide coadsorbed onto Ni(100). Surf. Sci. 1992, 273, 73-87.

50. Lin, C.-H.; Chen, C.-L.; Wang, J.-H. Mechanistic studies of water-gas-shift reaction on transition metals. J. Phys. Chem. C 2011, 115, 18582-18588.

51. Koverga, A.A.; Frank, S.; Koper, M. Density functional theory study of electric field effects on CO and $\mathrm{OH}$ adsorption and co-adsorption on gold surfaces. Electrochim. Acta 2013, 101, 244-253.

52. Politano, A.; Chiarello, G. Vibrational investigation of catalyst surfaces: Change of the adsorption site of CO molecules upon coadsorption. J. Phys. Chem. C 2011, 115, 13541-13553.

53. Politano, A.; Chiarello, G.; Benedek, G.; Chulkov, E.; Echenique, P. Vibrational spectroscopy and theory of alkali metal adsorption and co-adsorption on single-crystal surfaces. Surf. Sci. Rep. 2013, 68, 305-389.

54. Fleischer, I.; Popolan, D.M.; Krstić, M.; Bonačić-Koutecký, V.; Bernhardt, T.M. Composition dependent selectivity in the coadsorption of $\mathrm{H}_{2} \mathrm{O}$ and $\mathrm{CO}$ on pure and binary silver-gold clusters. Chem. Phys. Lett. 2013, 565, 74-79.

55. Ayastuy, J.; Gutierrez-Ortiz, M.; González-Marcos, J.; Aranzabal, A.; Gonzalez-Velasco, J. Kinetics of the low-temperature WGS reaction over a $\mathrm{CuO} / \mathrm{ZnO} / \mathrm{Al}_{2} \mathrm{O}_{3}$ catalyst. Ind. Eng. Chem. Res. 2005, 44, 41-50.

56. Kresse, G.; Hafner, J. Ab initio molecular dynamics for liquid metals. Phys. Rev. B 1993, 47, 558.

57. Kresse, G.; Hafner, J. $A b$ initio molecular-dynamics simulation of the liquid-metal-amorphous-semiconductor transition in germanium. Phys. Rev. B 1994, 49, 14251.

58. Kresse, G.; Furthmüller, J. Efficiency of ab-initio total energy calculations for metals and semiconductors using a plane-wave basis set. Comput. Mater. Sci. 1996, 6, 15-50.

59. Kresse, G.; Furthmüller, J. Efficient iterative schemes for ab initio total-energy calculations using a plane-wave basis set. Phys. Rev. B 1996, 54, 11169.

60. Perdew, J.P.; Burke, K.; Ernzerhof, M. Generalized gradient approximation made simple. Phys. Rev. Lett. 1996, 77, 3865.

61. Pan, Y.; Zhang, H.; Shi, D.; Sun, J.; Du, S.; Liu, F.; Gao, H. Highly ordered, millimeter-scale, continuous, single-crystalline graphene monolayer formed on $\mathrm{Ru}(0001)$. Adv. Mater. 2009, 21, 2777-2780. 
62. Blöchl, P.E. Projector augmented-wave method. Phys. Rev. B 1994, 50, 17953.

63. Monkhorst, H.J.; Pack, J.D. Special points for Brillouin-zone integrations. Phys. Rev. B 1976, 13, 5188-5192.

64. Nørskov, J.K.; Bligaard, T.; Hvolbæk, B.; Abild-Pedersen, F.; Chorkendorff, I.; Christensen, C.H. The nature of the active site in heterogeneous metal catalysis. Chem. Soc. Rev. 2008, 37, 2163-2171.

65. Pozzo, M.; Carlini, G.; Rosei, R.; Alfè, D. Comparative study of water dissociation on Rh(111) and Ni(111) studied with first principles calculations. J. Chem. Phys. 2007, 126, 164706.

66. Hansen, H.A.; Rossmeisl, J.; Nørskov, J.K. Surface Pourbaix diagrams and oxygen reduction activity of Pt, $\mathrm{Ag}$ and $\mathrm{Ni}(111)$ surfaces studied by DFT. Phys. Chem. Chem. Phys. 2008, 10, 3722-3730.

67. Remediakis, I.N.; Abild-Pedersen, F.; Nørskov, J.K. DFT study of formaldehyde and methanol synthesis from $\mathrm{CO}$ and $\mathrm{H}_{2}$ on $\mathrm{Ni}(111)$. J. Phys. Chem. B 2004, 108, 14535-14540.

68. Mittendorfer, F.; Hafner, J. Hydrogenation of benzene on Ni(111) a DFT study. J. Phys. Chem. B 2002, 106, 13299-13305.

69. Loffreda, D.; Simon, D.; Sautet, P. Vibrational frequency and chemisorption site: A DFT-periodic study of NO on Pd(111) and Rh(111) surfaces. Chem. Phys. Lett. 1998, 291, 15-23.

70. Henkelman, G.; Uberuaga, B.P.; Jónsson, H. A climbing image nudged elastic band method for finding saddle points and minimum energy paths. J. Chem. Phys. 2000, 113, 9901.

71. Henkelman, G.; Jónsson, H. Improved tangent estimate in the nudged elastic band method for finding minimum energy paths and saddle points. J. Chem. Phys. 2000, 113, 9978-9985.

72. Chorkendorff, I.; Niemantsverdriet, J.W. Concepts of Modern Catalysis and Kinetics, 2nd ed.; Wiley: Weinheim, Germany, 2006.

73. Van Harrevelt, R.; Honkala, K.; Nørskov, J.K.; Manthe, U. The reaction rate for dissociative adsorption of $\mathrm{N}$ on stepped $\mathrm{Ru}(0001)$ : Six-dimensional quantum calculations. J. Chem. Phys. 2005, $122,234702$.

74. Shannon, R.T.; Prewitt, C.T. Effective ionic radii in oxides and fluorides. Acta Cryst. 1969, 25, 925-946.

(C) 2013 by the authors; licensee MDPI, Basel, Switzerland. This article is an open access article distributed under the terms and conditions of the Creative Commons Attribution license (http://creativecommons.org/licenses/by/3.0/). 